\title{
Efficient Tour Planning for Tourist Sites Visitation in Lokoja, Nigeria: A Multi-Scenario Analysis Using GIS
}

\author{
Eleojo Oluwaseun Abubakar ${ }^{1,2}$, Ojochenemi Idoko',3, Ogbaje Stephen Ocholi ${ }^{1}$ \\ ${ }^{1}$ Department of Geography and Environmental Studies, Kogi State University, Anyigba, Nigeria \\ ${ }^{2}$ School of Geography, Politics and Sociology, Newcastle University, Newcastle upon Tyne, UK \\ ${ }^{3}$ Department of Environmental Studies, School of Tourism, Hospitality, and Environmental Management, University Utara \\ Malaysia, Sintok, Malaysia \\ Email: ${ }^{* i n f o 4 e l e @ y a h o o . c o m ~}$
}

How to cite this paper: Abubakar, E.O. Idoko, O. and Ocholi, O.S. (2017) Efficient Tour Planning for Tourist Sites Visitation in Lokoja, Nigeria: A Multi-Scenario Analysis Using GIS. Journal of Geographic Information System, 9, 59-81.

https://doi.org/10.4236/jgis.2017.91005

Received: November 26, 2016

Accepted: February 25, 2017

Published: February 28, 2017

Copyright $\odot 2017$ by authors and Scientific Research Publishing Inc. This work is licensed under the Creative Commons Attribution International License (CC BY 4.0).

http://creativecommons.org/licenses/by/4.0/

\begin{abstract}
This study used GIS to analyse various visitation sequence and routes for tourist sites in Lokoja considering multiple scenarios. This was done with a view to determining the most efficient visitation sequence vis-à-vis the routes for optimizing the overall visiting time and distance for the various scenarios considered. The main datasets used were the transportation network and the geographic coordinates of the tourist sites. These were collected through a comprehensive field survey of the study area. The ArcGIS 10.1 Network Analyst Extension was the main software used for this analysis. Five scenarios were considered comprising open and closed tours as well as Sequential Ordering Problems (SOP) and non-SOPs. In addition, for the first and second scenarios, an auxiliary scenario was considered that featured a hypothetical road block on an important arterial route. The fifth scenario considered the implication of a hypothetical flooding of some road sections along the bank of the River Niger. Furthermore, for each scenario, there were two optimization solutions: One that optimized the distance covered in visiting all the tourist sites and the other that optimized the time duration required to complete the site visitations. Optimal visitation sequences were determined by the network analyst as part of the solution of the respective scenarios. Sensitivity analysis was also performed to compare the consequences of time savings vis-à-vis distance savings across the various scenarios. In addition to the detailed navigation map produced for each scenario, a comprehensive navigation description guide was derived. The study reveals that scenarios where the site visitation sequence were optimized saved both time and distance markedly compared to scenarios with a predefined site visitation sequence. In all cases, shorter visitation durations were associated with time-optimized scenarios compared to distance-optimized ones while shorter visitation distances were
\end{abstract}


associated with distance-optimized scenarios as compared to time-optimized scenarios. However, the disparities between distance-optimized and timeoptimized scenarios were negligible in some cases. Furthermore, the blockage of an important arterial route (including the flooding of a vulnerable road segment) resulted in a striking increase in the optimal distance and time required to visit all the tourist sites in Lokoja. Overall, the shortest cumulative travel time (of approximately 17.69 minutes) and distance (of 15,897.20 meters) were derived from the second scenario.

\section{Keywords}

Tourism, Tour Planning, GIS, Network Analysis, Nigeria

\section{Introduction}

Information plays a very important role in the travelling decisions of individuals [1] [2]. This role have been investigated in several contexts [3] including route guidance [4], provision of tourist information [5] and highway congestion and incident related information [6]. In itinerary planning for performing daily activities, determining how and when to reach activity locations in an efficient way considering constraints of decision making is an important issue people are faced. Tourism is a typical application of this problem. Planning a travel route before starting the travel is a common requirement of a tourist [7]. This becomes a necessity where more and more people tend to travel to unfamiliar places in local and foreign countries. Maps become a vital component of travel planning. Whether finding a simple route between two locations or one that visits several locations, people usually try to take the best route. But best route can mean different things in different situations. The best route can be the quickest, shortest, or most scenic route, depending on the impedance chosen. Travelling to a tourist attraction can be understood based on two tour segments; 1) travel to the destination and 2) travel within the destination. Travelling within the destination may involve visiting several places of interests, restaurants, hotels etc. which needs to be visited in one tour. The destination can be reduced to a city for easy interpretation. Before tourists embark on a visit of multiple potential sites (especially within a destination), it is often the case that they have a plan of their intended visits especially for unfamiliar tourist sites. Such visitation plans are often called itineraries. Itineraries that are manually made are often grossly inefficient as there are usually very poor bases for making decisions of what the optimal routes to take are as well as what the best visitation sequence of sites should be. As a consequence, there is the attendant increase in cost as well as a reduction in other service productivity measures. Furthermore, where time-sensitive site visitation is required, there is no guarantee of timeliness. Hence, there is the need to employ the more efficient methods of multi-site tour planning offered by GIS.

GIS have been increasingly used as an efficient tool for a wide range of applications over the past decade including emergency response and transportation 
planning and management. GIS has evolved beyond the initial stages of data management and mapping, and have advanced into spheres such as modelling and analysis, thus facilitating spatial decision making. GIS technology offers great opportunities for the development of modern tourism applications using maps. Tourists who want to visit the sightseeing destination need to have information and visual representation about those places with the help of GIS tools. This technology integrates common database operations such as query with the unique visualization and geographic analysis benefits offered by maps [8]. Determining the shortest and best route between the various tourist places from their accommodation is beneficial for tourist in terms of time and economy. The generation of optimal routes for visiting multiple tourist sites is enabled by network analysis. Network analysis is the burgeoning field in tourism for better planning and development. Network analysis is also invaluable for the management of network facilities like utility/transmission lines/cables, transport systems, retail store planning and also for tourism route planning. GIS enabled network analyses help the tourist to plan and view spatially the routes to visit tourist places in the shortest time and distance. Hence, travel-related agencies may develop well-designed, informative and ready-to print maps to enhance visitors' travel experiences. GIS can make it easier for visitors to find their way around their destinations. Using the Internet, it is possible to provide prospective visitors with visualizations of the desired destination. Combining photos, sounds and video clips with mapping technology, visitors can plan their trips ahead of time [9]. Hence, GIS is very useful for the management, analysis and visualization of the spatial and temporal components of transportation systems and in trip patterns [10] [11].

Route planning has been an active research area in transportation and logistics. Traditional route choice involves finding the shortest or the fastest route between any two given points [12]. The shortest route is obtained by minimizing the distance between the origin and the destination point; while the fastest route is obtained by minimizing the travel time between those points. The travel time between any two given points $\mathrm{A} \& \mathrm{~B}$ is stochastic in nature (ibid). It may depend on many variables such as traffic on that route, congestion, traffic incidents, weather, scenic beauty etc. Any cost attribute can be chosen as the impedance, which is particularly minimized while determining the route [13]. If the impedance is time, then the best route is the quickest route. Hence, the best route can be defined as the route that has the lowest impedance, where the impedance is chosen by the user. Any valid network cost attribute can be used as the impedance when determining the best route [14]. Furthermore, the fastest route during off-peak hours may not be the fastest route during the peak hours.

Several attempts have been made to integrate different models into GIS and combine GIS with the development of Intelligent Transportation System (ITS) [15]. Bi-level Genetic Algorithm (GA) and Geographic Information System (GIS) was used to derive a route in a given transportation network which satisfy multiple objectives such as, minimal cost, minimum travel time, etc [16]. Using 
Dijkstra's algorithm, a route planning methodology of an Advanced Traveller Information System (ATIS) was developed and successfully implemented for the Vilnius city [17]. ATIS is very important as it presents information on real time traffic which can be used to predict traffic congestion thereby allowing travellers to make better decisions for their trip based on their preference of shortest or fastest route. A Standard ESRI ArcGIS Server Network extension was setup which enabled users to perform real-time optimal route calculation tasks via a WEB based information systems application. The WEB application allows users to input their trip information and also allows them to include restrictions on their trip (e.g. travelling from $\mathrm{A}$ to $\mathrm{C}$ with a stopover at a point $\mathrm{B}$ ). When submitted it shows the optimal route (both fastest and shortest) on a GIS map and it also gives public transport as an alternative option for the trip.

Enhancements to the capacities of existing GIS software makes the planning of multi-site visits expedient under the category of problems often dubbed the Shortest Path (SP) problem and the Travelling Salesman Problem (TSP). The classic SP problem consists of finding, in an oriented graph, a feasible path that links a given origin node to a given destination node and minimizes the sum of its arc costs [18]. Computer-based trip planning frequently employs optimal path (or shortest path) algorithms. Typical algorithms for computing shortest paths are those of Dijkstra [19], Dantzig [20] and Bellman Ford [21]. Other SP algorithms include the $\mathrm{A}^{*}$ algorithm. Several other algorithms exist for finding shortest paths between two known locations, based on different cost factors; hence, when faced with the task of computing shortest paths, one must decide which algorithm to choose [22]. The development, computational testing, and efficient implementation of shortest path algorithms have remained important research topics within related disciplines such as operations research, management science, geography, transportation, and computer science [19] [23] [24] [25] [26]. Among the evaluations of shortest path algorithms [22] [27] [28] [29], a study by Cherkassky et al. [29] is the most comprehensive. Incidentally, most GIS packages do not provide information on the algorithms used for this class or any similar network analysis problems, nor references to indicate the procedures used [30]. Only the experience of using a particular implementation will confirm the nature of its behaviour, both in terms of computational complexity (time and space) and quality (optimality).

SP analysis is a subset of a more general class of problems known as the Traveling Salespersons Problem (TSP) [31]. Given a set of vertices and symmetric or asymmetric distance matrix for each pair of vertices, the TSP seeks to find a Hamiltonian circuit of minimal length (cost). If certain nodes must be visited before others, the task is known as a Sequential Ordering Problem (SOP); but whichever the case, typically the start location (vertex) is pre-specified. TSP involves making a tour of every vertex in a given set, (returning to the starting point,) such that the tour length/time is minimized. The two types of tours associated with the TSP are the closed and the open tours [30]. An open tour is a connected series of shortest paths from $1-2,2-3$, and finally 3 - 4. It can also be 
seen as a shortest path from location 1 to location 4 , with the constraint that the route must go via locations 2 and 3-a very common requirement. A closed tour, returning to location 1 , could have been generated by adding a shortest path from location 4 to 1 . The foregoing tour may not optimal for the sequential condition (1 - 2 - 3 - 4), rather another sequence (say 1 - 4 - 3 - 2) may be optimal if the sequential condition is dropped. TSP is one of the main contemporary research problems that are very valuable with transportation networks. Applications include: salesmen visiting customers; rubbish trucks servicing business premises; delivery trucks servicing retail outlets; security staff patrolling premises and many more. Wijesinghe [7] presents an evaluation of the Dijkstra and TSP algorithms.

The objective of the optimal travel scenarios of this article is to minimize the sum of the travel distance or time required to visit the tourist sites in either a predefined or optimal order. This includes analysing various scenarios by which the various tourist sites in Lokoja could be visited. This is done with the view to demonstrating how GIS could be employed in planning efficient multi-site visits, with the attendant benefits highlighted in various section of this article. The conventional Traveling Salespersons Problem (TSP) algorithms are applied to a geo-enabled transportation network to find the optimum paths and optimum sites' visitation sequence.

This article will answer the following questions for each of the five different scenarios: how should tourists be routed optimally through the transportation network in order to optimize distance or time (this involves producing navigation direction guides for each scenario)? what distance/time will a tourist cover/spend in visiting all the tourist sites? what is the optimal visitation sequence for visiting all the tourist sites in the least possible time/distance; should there be a road block or flooding on an important connecting route on the transportation network, what other alternative routes are optimal to complete the site visitations?; how do the various scenarios compare and contrast to one another. Furthermore, In addition to a map of the resulting optimal route for each scenario, details of the travel distances and costs for each scenario will be presented and discussed.

The remainder of this article is organized as follows: a discussion of the properties of a network dataset in ArcGIS forms an important conceptual basis upon which a lot of subsequent analysis is based; a brief description of the study area follows; then the data types and data sources are described. The method by which the data were analysed is explained, followed by a presentation and discussion of results of the analysis; done for each scenario.

\section{The Properties of a Network Dataset in ArcGIS}

The network datasets are the data source which are used to do the Network Analyst in ArcGIS. It is created from various feature or types of data source which participate in this network. Besides, this network datasets incorporates an advanced connectivity model that is used to show complex scenarios, for example, the multimodal transportation networks [32]. The attributes of network 
datasets identify impedances, restrictions, and hierarchy of the network. The components of network datasets are usually lines, points and turns. These translate into the three kinds of network elements: edges, junctions, and turns. Edges are elements that connect to other elements (junctions). Junctions connect edges and facilitate navigation from one edge to another. Turn elements record information about movement between two or more edges [33]. Connectivity in a network dataset is based on geometric coincidences of line endpoints, line vertices, points and connectivity rules that you set as properties of the network dataset [34].

ArcGIS Network Analyst can find the best way to get from one location to another or the best way to visit several locations. The locations can be specified interactively by placing points on the screen, by entering an address, or by using points in an existing feature class or feature layer. In this way, the user can determine the best route based on a pre-specified order of locations. Alternatively, ArcGIS Network Analyst can determine the best sequence to visit the locations.

Network attributes are properties of the network elements that control traversability over the network [35]. Examples of attributes include the time to travel a given length of road, which streets are restricted for which vehicles, the speeds along a given road, and which streets are ruled only one-way. Turns can be made at any junction where edges connect. There are $n^{2}$ possible turns at every network junction, where $\mathrm{n}$ is the number of edges connected at that junction [36]. Even at a junction with a single edge, it is possible to make one U-turn.

\section{The Study Area}

Lokoja, the capital city of Kogi State, Nigeria is the study area for the article. It is located between Latitude $7^{\circ} 45^{\prime} 2 " \mathrm{~N}-7^{\circ} 51^{\prime} 22.5^{\prime \prime} \mathrm{N}$ and Long $6^{\circ} 41^{\prime} 19^{\prime \prime} \mathrm{E}-6^{\circ} 45^{\prime} 00^{\prime \prime} \mathrm{E}$; see Figure 1 for the map of the study area. It was chosen because of its popularity as a site of tourism especially of some famous European colonial monuments like those listed in Table 1. Also, as accelerated urban expansion are current urban concerns in the town, the existing roads have become congested. Table 1 shows the names that correspond to the alphabets denoting the tourist sites in the study area as depicted in Figure 1.

\section{Data Types and Sources}

The transportation network dataset and the geographic coordinates of the tourist sites were the main datasets used for this research. Relevant attributes of the transportation routes like road type and road name were also captured in the transportation network map. The coordinates of each of the tourist sites of interest together with the name of such sites was also documented. Both datasets were collected by a comprehensive fieldwork of the study area (in 2013) using a handheld Global Positioning System (GPS) receivers.

\section{Method of Data Analysis}

The ArcGIS 10.0 desktop software was the main analysis software used; the research specifically relied on the network analyst suite of the same software. The 


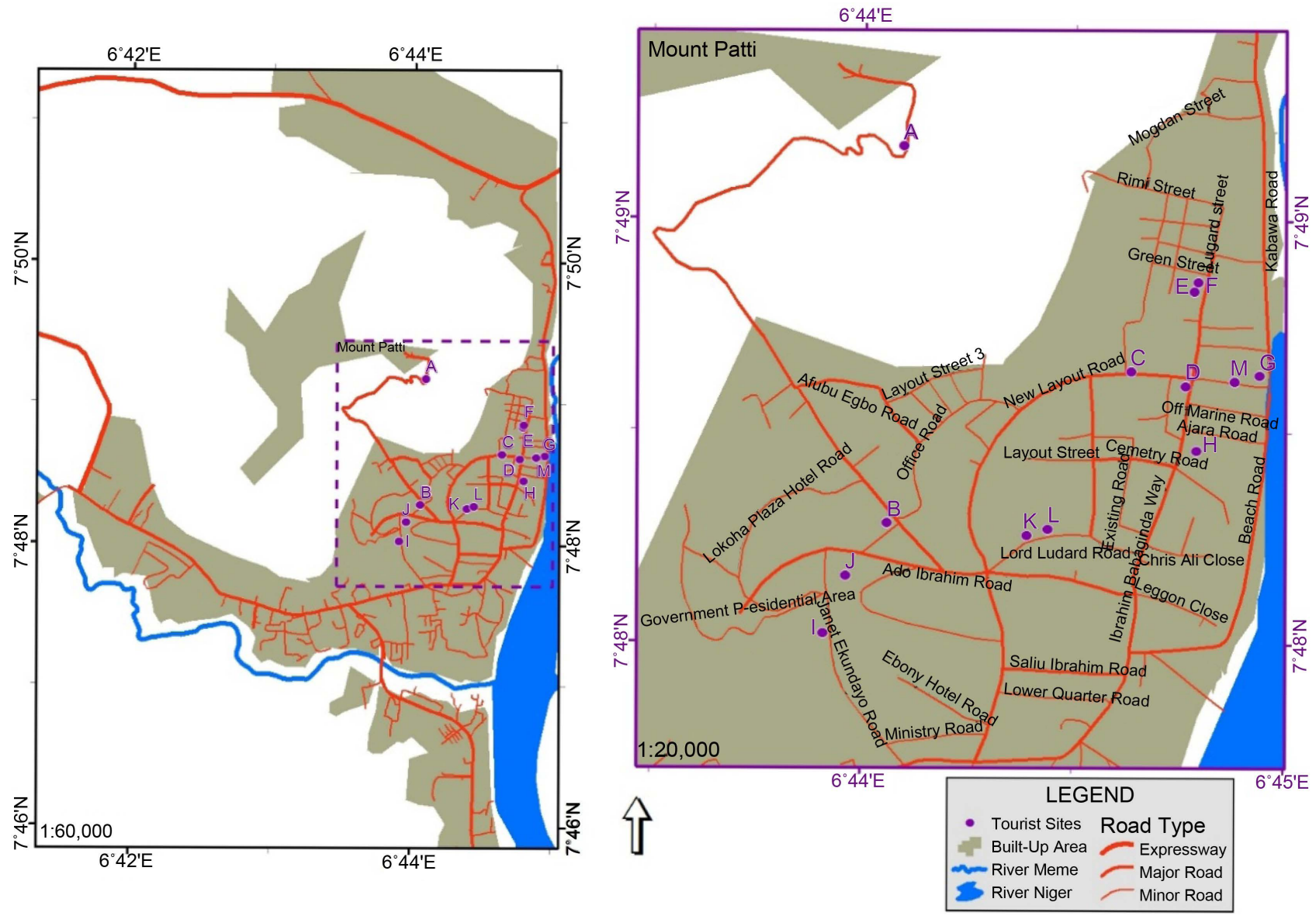

Figure 1. Map of the study area showing the locations of the tourist sites.

Table 1. Names and coordinates of the tourist sites in the study area (see also Figure 1).

\begin{tabular}{ccccc}
\hline Key & Name & Latitude (dd) & Longitude (dd) & Elevation (m) \\
\hline A & Lugard Rest House & 7.81953 & 6.73495 & 404 \\
B & Club 1901 & 7.80468 & 6.73437 & 99 \\
C & Spot of Royal Niger Company & 7.81072 & 6.74397 & 73 \\
D & Lugard Save & 7.81014 & 6.74613 & 69 \\
E & 1st Primary School & 7.81389 & 6.74644 & 69 \\
F & Iron of Liberty & 7.81424 & 6.7466 & 64 \\
G & UAC Warehouse & 7.81057 & 6.74905 & 57 \\
H & European Cemetry & 7.80759 & 6.74657 & 64 \\
I & Lugard House (Government House) & 7.80034 & 6.7319 & 89 \\
J & 1st Prison Yard in Northern Nigeria & 7.80261 & 6.73275 & 104 \\
K & Kogi StateTourism Board & 7.80424 & 6.7399 & 84 \\
L & National Museum & 7.80448 & 6.74074 & 74 \\
M & Grave of Deposed Emir of Kano & 7.81032 & 6.74806 & 60 \\
\hline
\end{tabular}

ArcGIS was used the model the transportation route, analyse the optimal routes connecting the various tourist sites under the scenarios considered as well as produced maps that show the results of the various analysis conducted. The Mi- 
crosoft Excel 2013 software was also used in collating and presenting some of the statistics relevant to this project.

Five scenarios were considered to guide potential future tourists in decision making as regards tourist site visitations in Lokoja. These scenarios are presented and discussed in the subsequent section. The multiple scenarios also helped to analyse the robustness of the transportation network model developed. In all cases, optimization was done for time and distance. The cumulative distance and time for each scenario were analysed and details of the respective routing directions were documented. Hypothetical average speeds for the different road types in the study area were modelled as attributes of the network dataset as follows: express roads, $80 \mathrm{~km} / \mathrm{h}$; major roads, $60 \mathrm{~km} / \mathrm{h}$ and minor roads, $40 \mathrm{~km} / \mathrm{h}$.

\section{Presentation and Discussion of Results}

The summary of the findings of the different scenarios is presented on Table 2. The " $b$ " versions of the respective scenarios are options wherein a hypothetical road block scenario was considered. For each scenarios, distance-optimized as well as time-optimized versions were presented. For most scenarios, the cumulative distance covered for distance-optimized versions were shorter than those covered by the time-optimized versions. Conversely, the cumulative time duration associated with the time-optimized scenarios was shorter than those for the distance-optimized scenarios. Overall, the shortest distance required to complete visiting all the tourist sites was 15,897.20 meters recorded by the second scenario (a closed non-SOP) while the shortest time duration required to complete visiting all the same tourist sites was 17.69 minutes recorded by the same second scenario. As expected, it was also observed that in addition to the gains (savings) associated with the distance and time optimizations, there were better savings (or gains) in both time and distance when the visitation sequence of the tourist sites were optimized (i.e. non-SOPs as determined by the network analyst software extension) as compare to the savings associated with scenarios of a predetermined visiting sequence (SOPs). Of all the scenarios, the greatest distance and time savings achieved were 227.87 meters and 0.46 minutes respectively, both of which were recorded by the first scenario (with a road block considered).

Table 2. A summary of the quantitative details about all the scenarios.

\begin{tabular}{|c|c|c|c|c|c|c|c|c|}
\hline \multirow{2}{*}{ Scenarios } & \multicolumn{4}{|c|}{ Distance-Optimized Version Time-Optimized Version } & \multicolumn{2}{|c|}{ Distance-Optimized Minus Time-Optimized } & \multirow{2}{*}{\multicolumn{2}{|c|}{ Problem Type Tour Type }} \\
\hline & Distance $(\mathrm{m})$ & Time (mins) & Distance $(\mathrm{m})$ & Time (min) & Distance $(\mathrm{m})$ & Time (mins) & & \\
\hline 1 & $20,929.92$ & 24.08 & $21,136.62$ & 23.80 & -206.70 & 0.2809 & SOP & Closed \\
\hline $1 b$ & $23,048.08$ & 27.15 & $23,275.95$ & 26.69 & -227.87 & 0.4605 & SOP & Closed \\
\hline 2 & $15,897.20$ & 17.69 & $15,897.20$ & 17.69 & 0.00 & 0.0005 & Non-SOP & Closed \\
\hline $2 b$ & $16,037.84$ & 18.35 & $16,037.84$ & 18.35 & 0.00 & 0.0002 & Non-SOP & Closed \\
\hline 3 & $22,525.34$ & 25.60 & $22,728.65$ & 25.32 & -203.31 & 0.2860 & SOP & Open \\
\hline 4 & $16,834.63$ & 18.41 & $16,841.09$ & 18.13 & -6.46 & 0.2763 & Non-SOP & Open \\
\hline 5 & $16,138.10$ & 18.07 & $16,138.10$ & 18.07 & 0.00 & 0.0005 & Non-SOP & Open \\
\hline
\end{tabular}


Subsequent paragraphs provide further discussions about each of the various scenarios considered in this study. For each scenario, there is an associated figure that shows the routes to take to complete visiting all the tourist sites. The visitation sequence for each scenario is also depicted in the associated figures as numbers in circles for each of the respective tourist locations. Also, there is a graph associated with each scenario that helps to compare distance-optimized scenarios with time-optimized ones. Lastly, for each figure, there is an accompanying tour directions guide that textually and graphically aides navigating the routes while visiting the tourist sites. To minimize the length of this article, all but the directions guide of the $2^{\text {nd }}$ scenario were not included in this article.

In reality, a tourist is very likely to commence the visitations of sites from a particular origin (for example a hotel, an entry/exit route, an events centre, a tourist registration point or any other stipulated place) and finish the visitations at the same (i.e. a closed tour) or a different place (i.e. an open tour). The commencement and finishing points may even in themselves be tourist sites (such as where a tourist site contains accommodation facilities). As such, there is often the need to predefine such stipulated commencement and finishing points (sites) especially when a scenario entails optimizing the visitation sequence of the tourist sites in the tour (i.e., non-sequential ordering problems). Hence, for all scenarios (but the last-Scenario 5) that were closed tours and SOPs, the only university in the study area (i.e. the Federal University, Lokoja) was hypothetically predetermined as the commencement and finishing point for the tours. Note that this location was not one of the tourist sites and so any other place like a hotel, a private residence, an entry point into a city, a restaurant etc. could be specified instead. Scenario 5 was an exception to this criteria because it was an open tour, so the tourists were hypothetically assumed to finish their tours enroute Abuja.

Scenario 1: This is an SOP as well as a closed tour. As shown in Figure 2 and Figure 3 and the associated statistics presented in Table 2; the time- and distance-optimized versions of this scenario produced different results. Hence, the routes traversed in visiting all the tourist sites in a predetermined order for the distance-optimized version are different to those of the time-optimized version. As such, while the distance-optimized version entailed a distance of 20,929.92 meters and a travelling duration of 24.08 minutes, the time-optimized scenario covered a distance of 1136.62 meters and a travelling duration of 23.80 minutes cumulatively. Figure $3(\mathrm{a})$ is a graph that compares the distance- and time-optimized versions in more details.

Once a hypothetical blockage of a major connecting route was introduced as shown in Figure 2(b), the travelling routes as well as visitation sequence of the tourist sites became considerably different to the former (i.e. Figure 2(a)). Also, the distance- and time-optimized versions produced slightly different results for the routes required to visit all the sites while the visitation sequence remained the same for both versions of this scenario. Here, 23,048.08 meters and 27.15 minutes was the distance and time respectively associated with visiting all the 


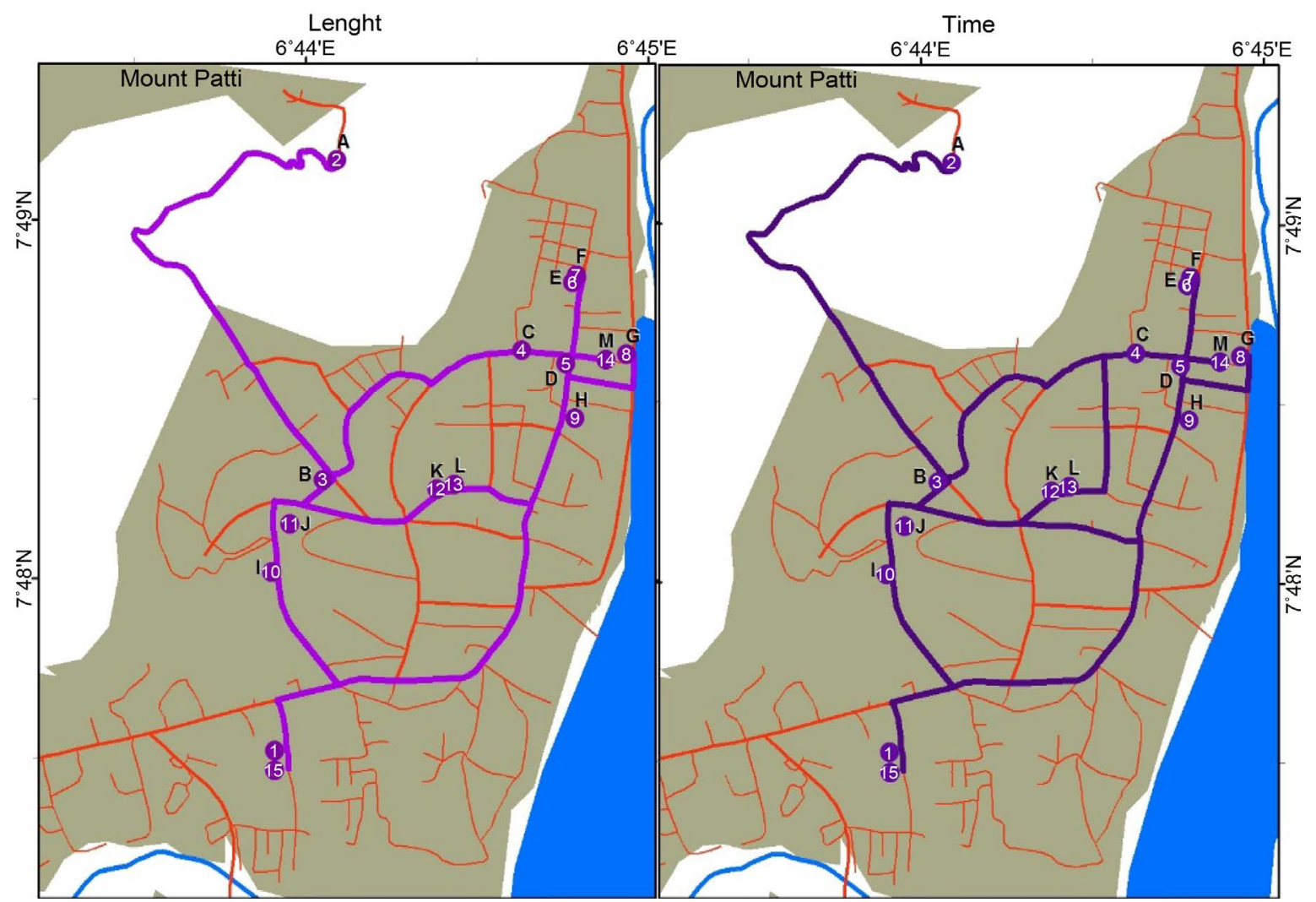

(a)

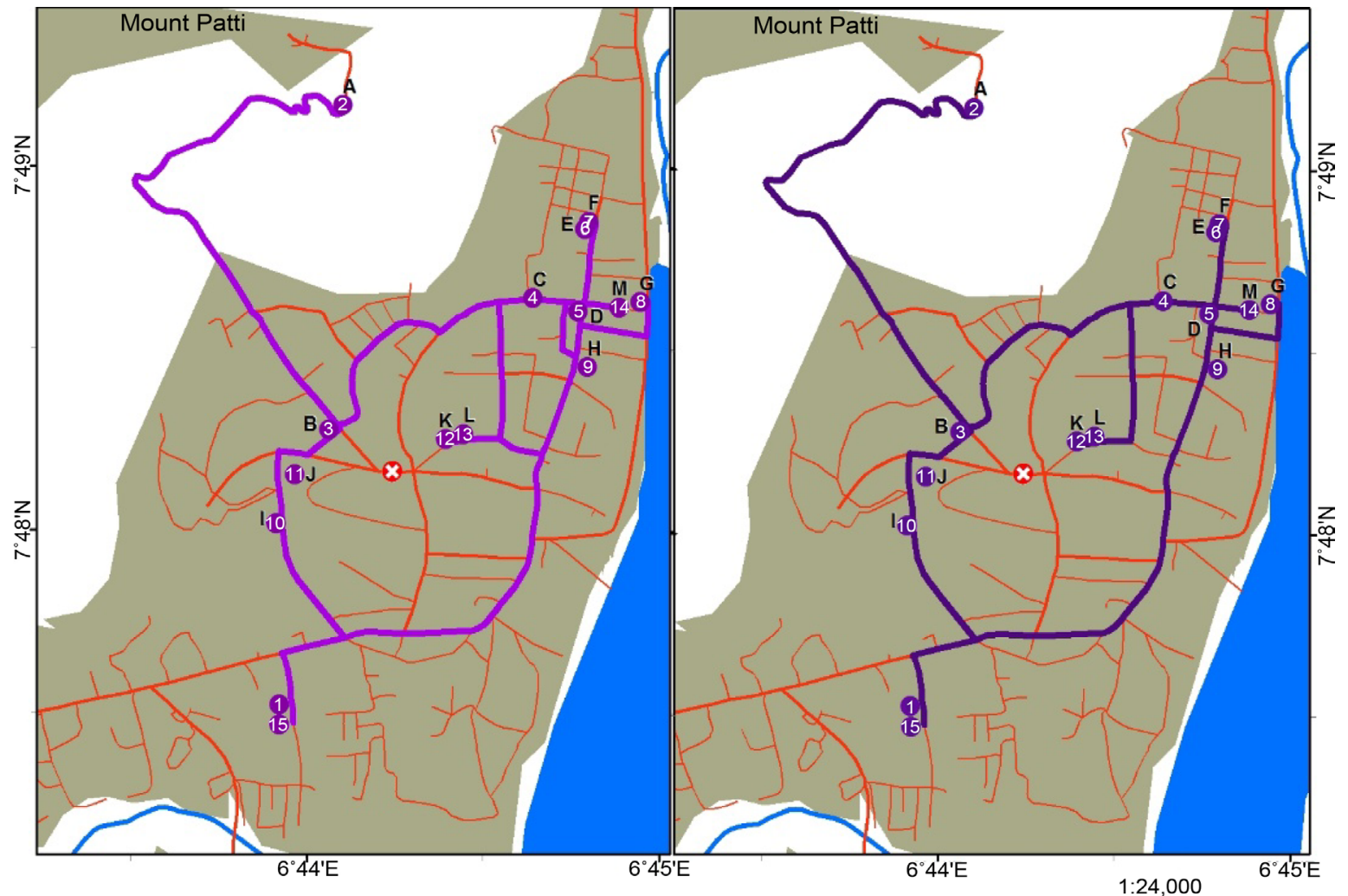

(b)

Figure 2. Maps of scenario 1: The LHS maps are distance-optimized versions while the RHS maps are time-optimized; the bottom maps are different from the top maps because they include a hypothetical road block. 

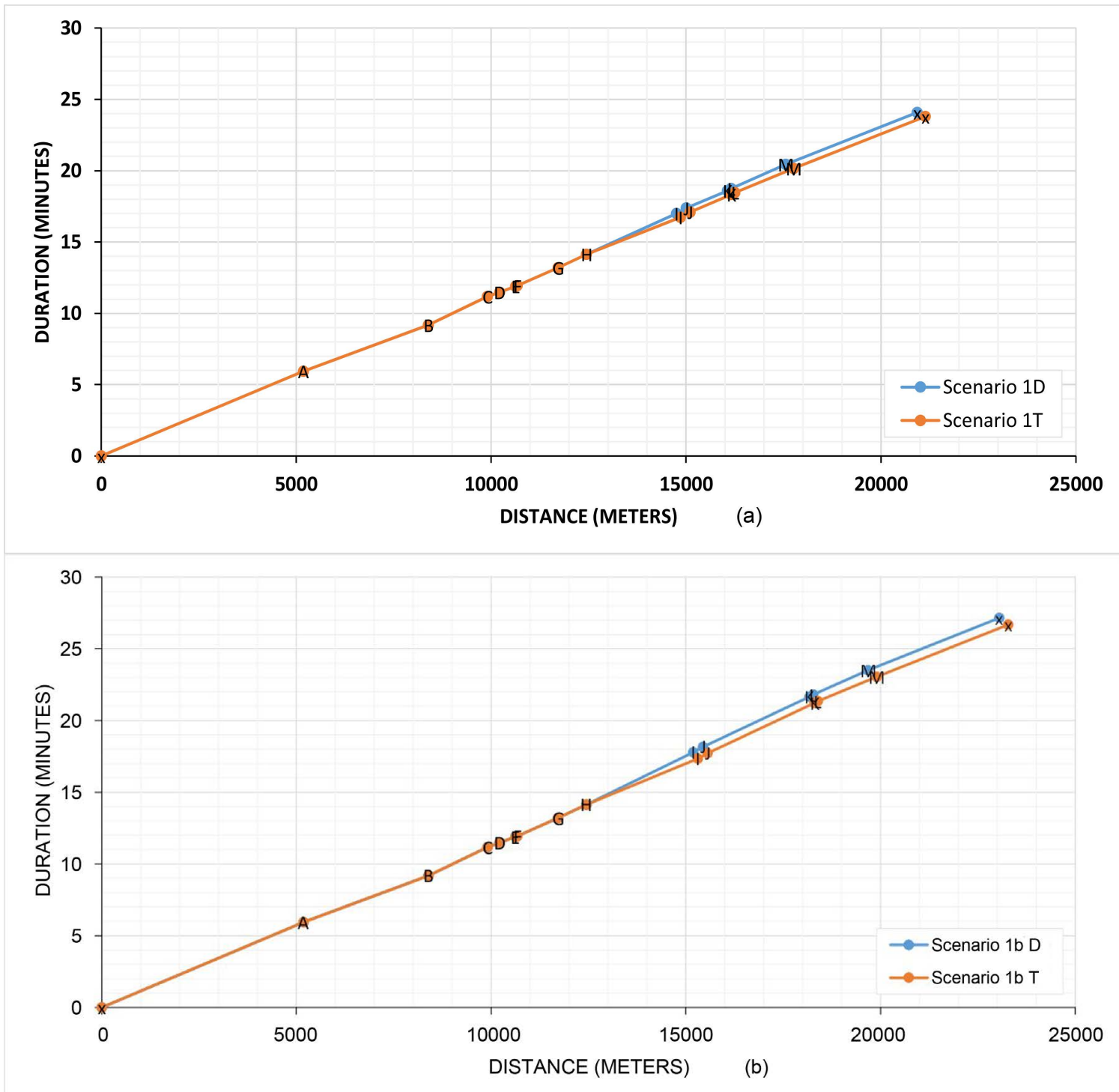

Figure 3. Graphs of scenario 1: The top graph (a) is the distance-time plot of the scenarios without a road block, while the bottom graph (b) shows a scenario with a hypothetical road block.

tourist sites under the distance-optimized version of this scenario; while 23,275.95 meters and 26.69 minutes was the distance and time respectively associated with traversing all the tourist sites in the time-optimized version of this scenario. See Figure 3(b) for a graph that compares the distance- and timeoptimized versions in more details.

These show that time-optimized versions produced better savings on travelling duration (compared to the distance-optimized versions) while distance-optimized version produced better saving on distance (compared to the time-optimized versions) as expected.

Scenario 2: This is a non-SOP as well as being a closed tour. In Figure 4 is a graphical rendition of the result of this scenario. Notice that the optimal visitation sequence remained identical for both the distance- and time-optimized versions. For the current scenario, the first tourist site visited when setting out from 


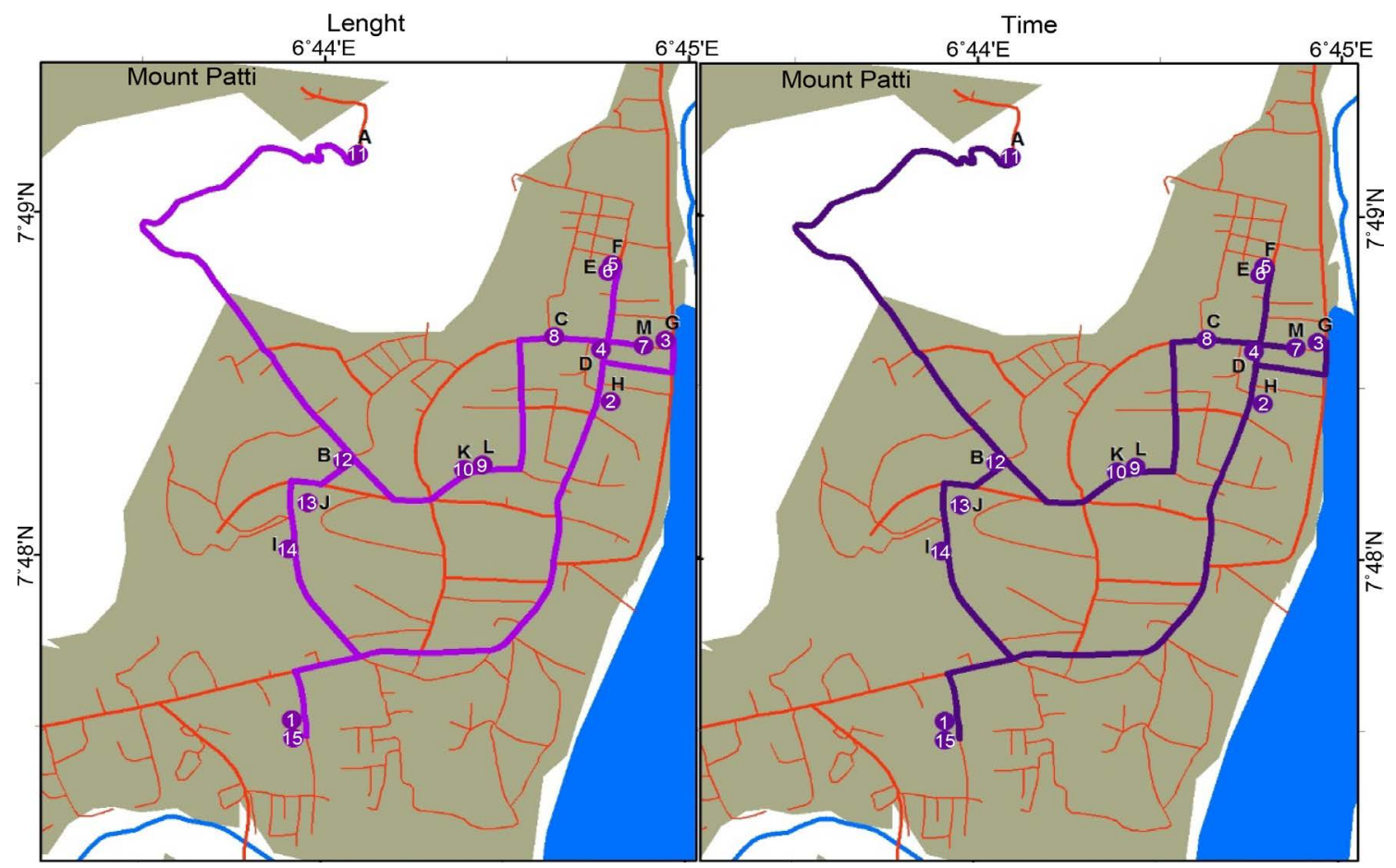

(a)

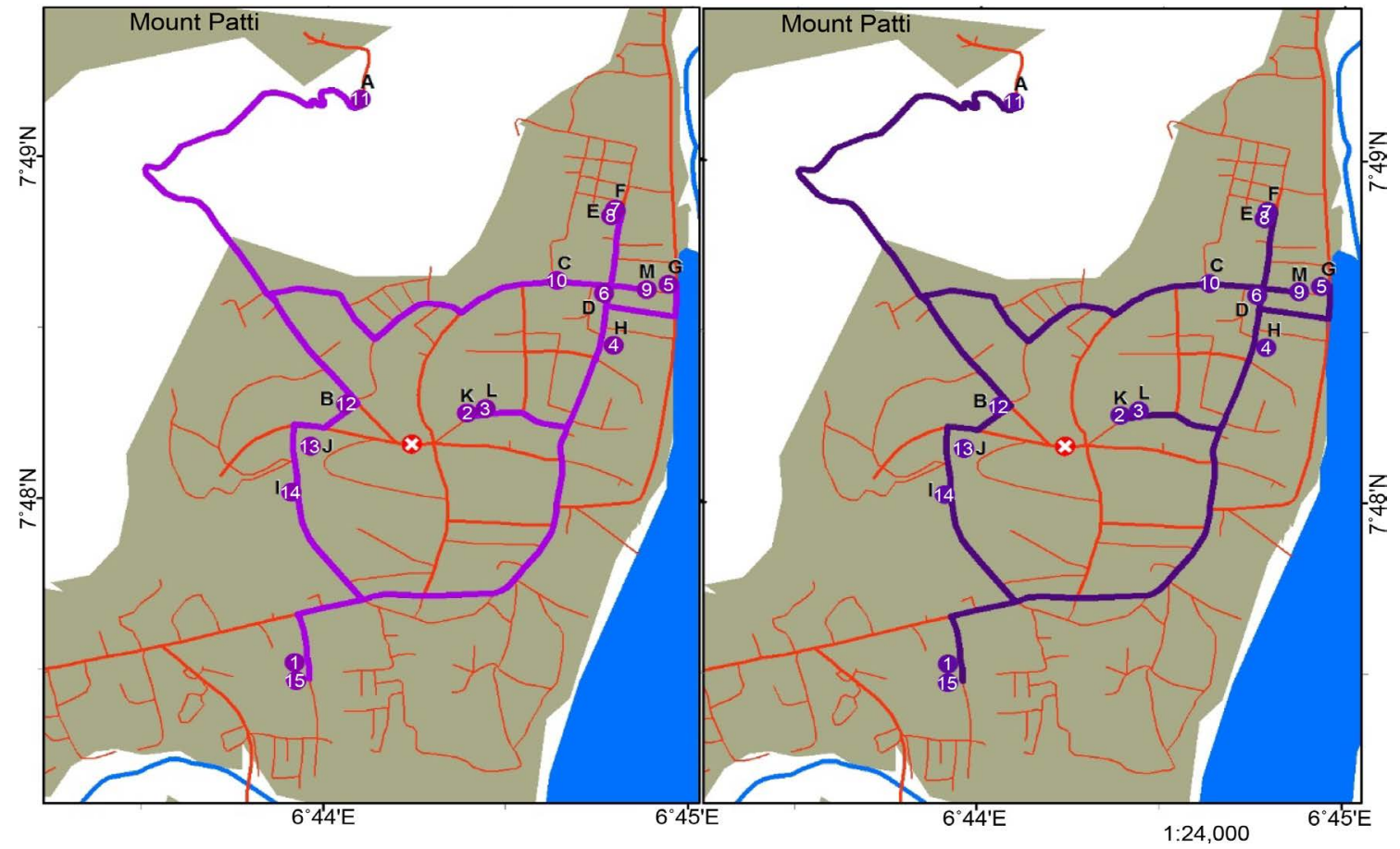

(b)

Figure 4. Maps of scenario 2: The LHS maps are distance-optimized versions while the RHS maps are time-optimized; the bottom maps are different from the top maps because they include a hypothetical road block.

the pre-specified origin was site " $H$ ", then " $G$ ", then " $D$ ", then others, with the last being site "I". For this scenario, the cumulative distances required to complete visiting all the tourist sites was 15,897.20 meters and 15,897.20 meters for the distance- and time-optimized versions respectively. Also, 17.69 minutes and 


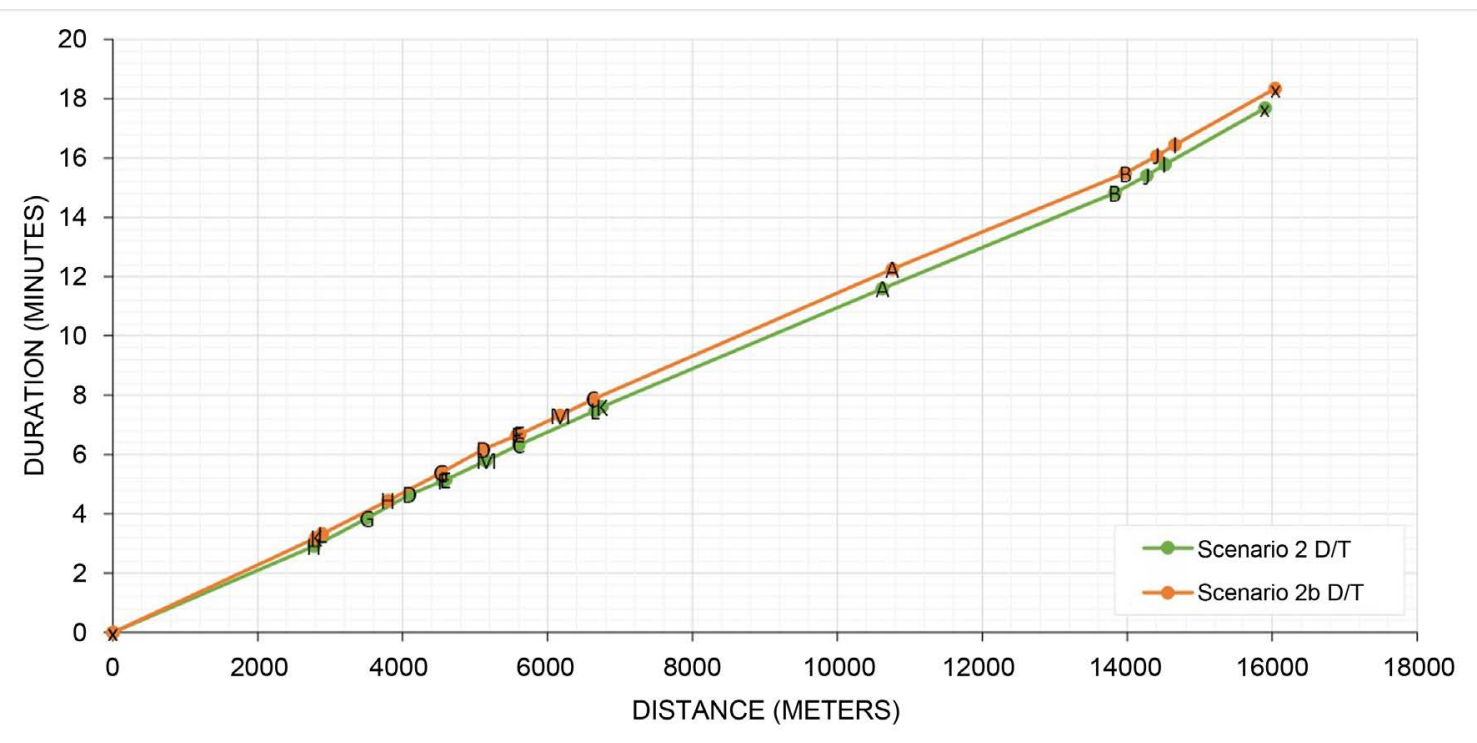

Figure 5. Graph of scenario 2: Distance- and time-optimized versions produced near identical results so each line represents these two versions of each scenario. The green line represents scenario without the hypothetical road block, while the red line represents the scenario the with the hypothetical road-block (b).

17.69 minutes is the associated time duration associated with the distance- and time-optimized versions respectively. Notice from the foregoing statistics that the difference in the optimal distance and time for both the distance- and time-optimized versions of this scenario is so infinitesimal and so is negligible. This shows also that there are certain instances when distance and time optimizations yield almost identical results. However, this may be expected only when the site visitation sequence is optimized (i.e. non-SOPs).

The initial part of the comprehensive navigation directions guide for this scenario was presented in Figure 6. Notice the details of turn directions for each junction on the navigation routes to the tourist sites; the names of all the navigation route; the distance and travel duration for each route segment and the map inset for every tourist site once reached. This is a very interesting feat of GIS-enabled optimal tour plans that make GIS an invaluable technology in itinerary planning and similar applications as buttressed in other sections of this article.

A further thrust to this second scenario is the introduction of a hypothetical road block on an important connecting route (see Figure 4(b)). Among other things, this scenario helped to support the assertion made in the preceding discussions that once the visitation sequence is optimized (especially when the take-off and arrival points are predefined - i.e. non-SOPs), the results for time and distance optimizations are often almost identical in terms of the actual routes taken, the cumulative distance involved as well as the respective cumulative visitation time. The routes traversed and the associated site visitation sequence for this scenario is presented in Figure 4. Figure 5 is a graph that compares the distance- and time-optimized versions in more details. For this scenario, the cumulative distance required to complete visiting all the tourist sites was $16,037.84$ meters and 16,037.84 meters for the distance- and time-optimized 


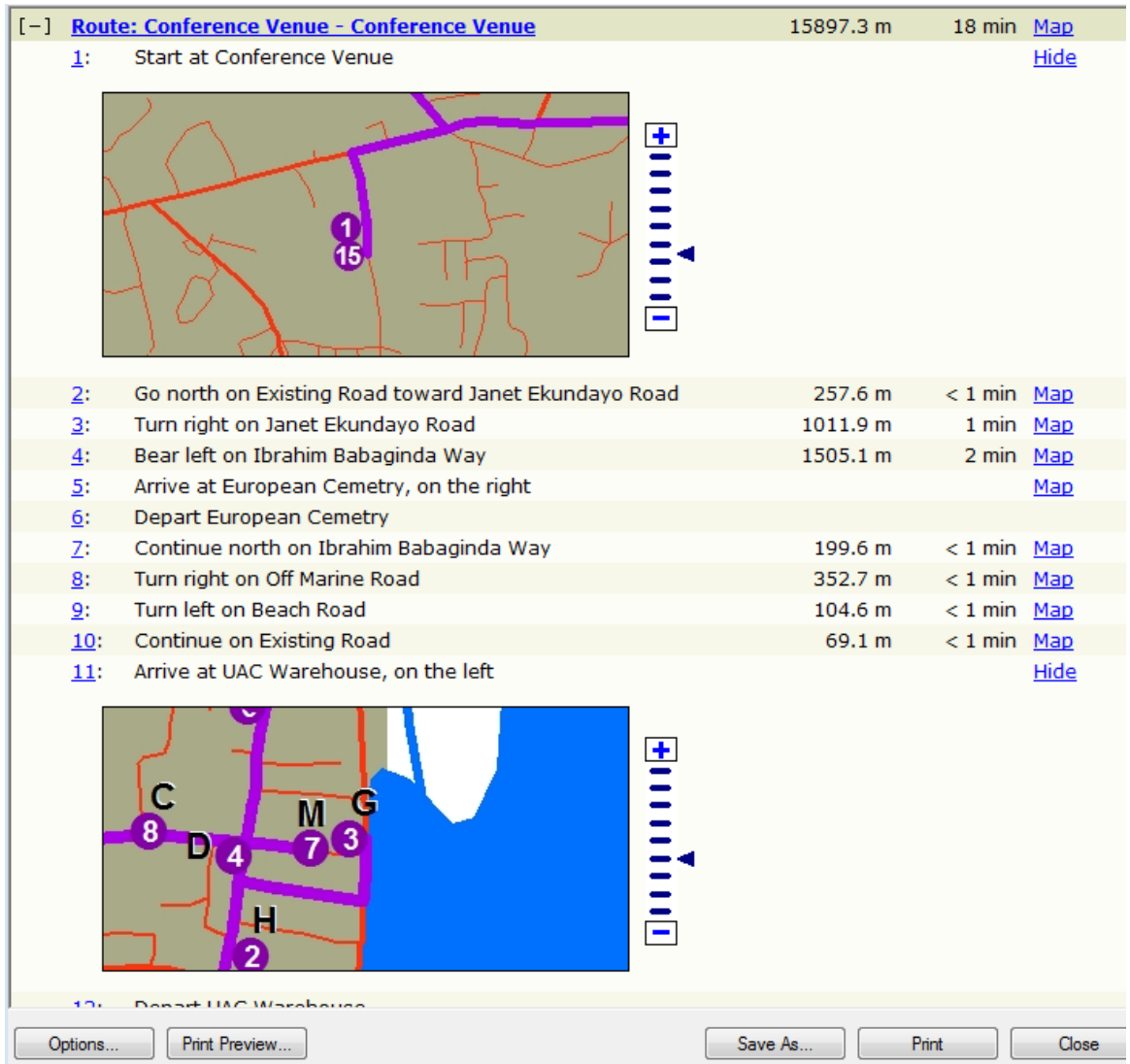

Figure 6. The navigation directions guide of scenario 2a.

versions respectively. Also, 18.35 minutes and 18.35 minutes was the associated time duration associated with the distance- and time-optimized versions respectively.

Comparing both cases of scenario 2 (i.e. with/without a road block) with both cases of scenario 1 , it could be observed that scenarios wherein the site visitation sequence were optimized (i.e. non-SOPs) yielded better results (in terms of savings in both distance and time), than SOP scenarios. Note however, that there are instances where a planned multi-site tour is so regimented that the optimization of the visitation sequence of sites is not practicable (i.e. a mandatory SOP).

Scenario 3: There are often instances when a tourist sets out for the visitation of sites from a predefined location but decides to proceed in another direction (different from his/her origin) after completing the tour. This was the case hypothesized by this scenario. Here, it was assumed that after a conference, participants decide to visit all the tourist sites in Lokoja (in a pre-determined order) before continuing their journey towards Abuja. Hence, this is an SOP as well as an open tour.

With a predetermined visitation sequence of the tourist sites, the routes for the distance- and time-optimized versions is graphically depicted in Figure 7(a). Notice that the optimal routes to traverse in visiting all the tourist sites changed considerably between the distance- and time-optimized versions as shown in Figure 7(a) (LHS vs RHS). 


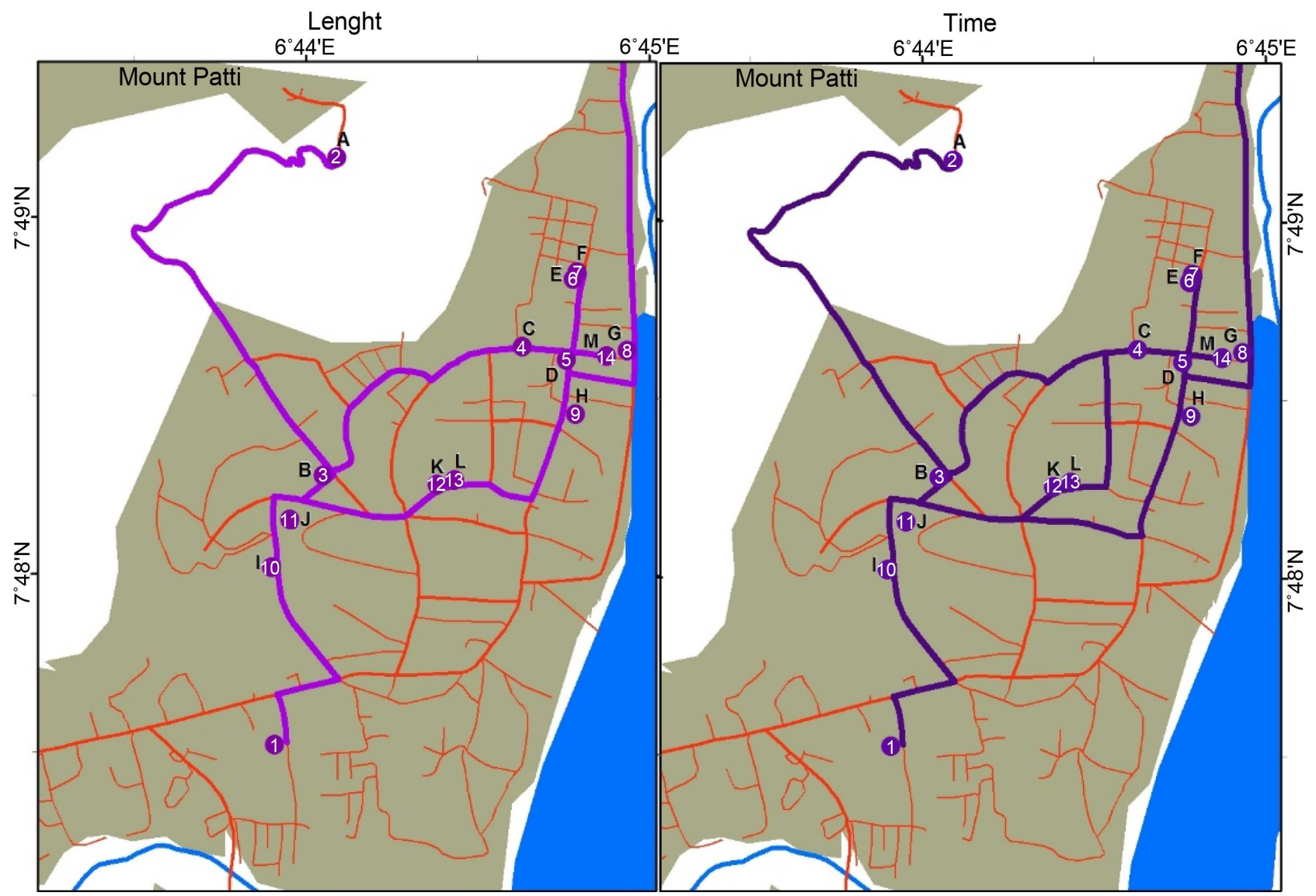

(a)
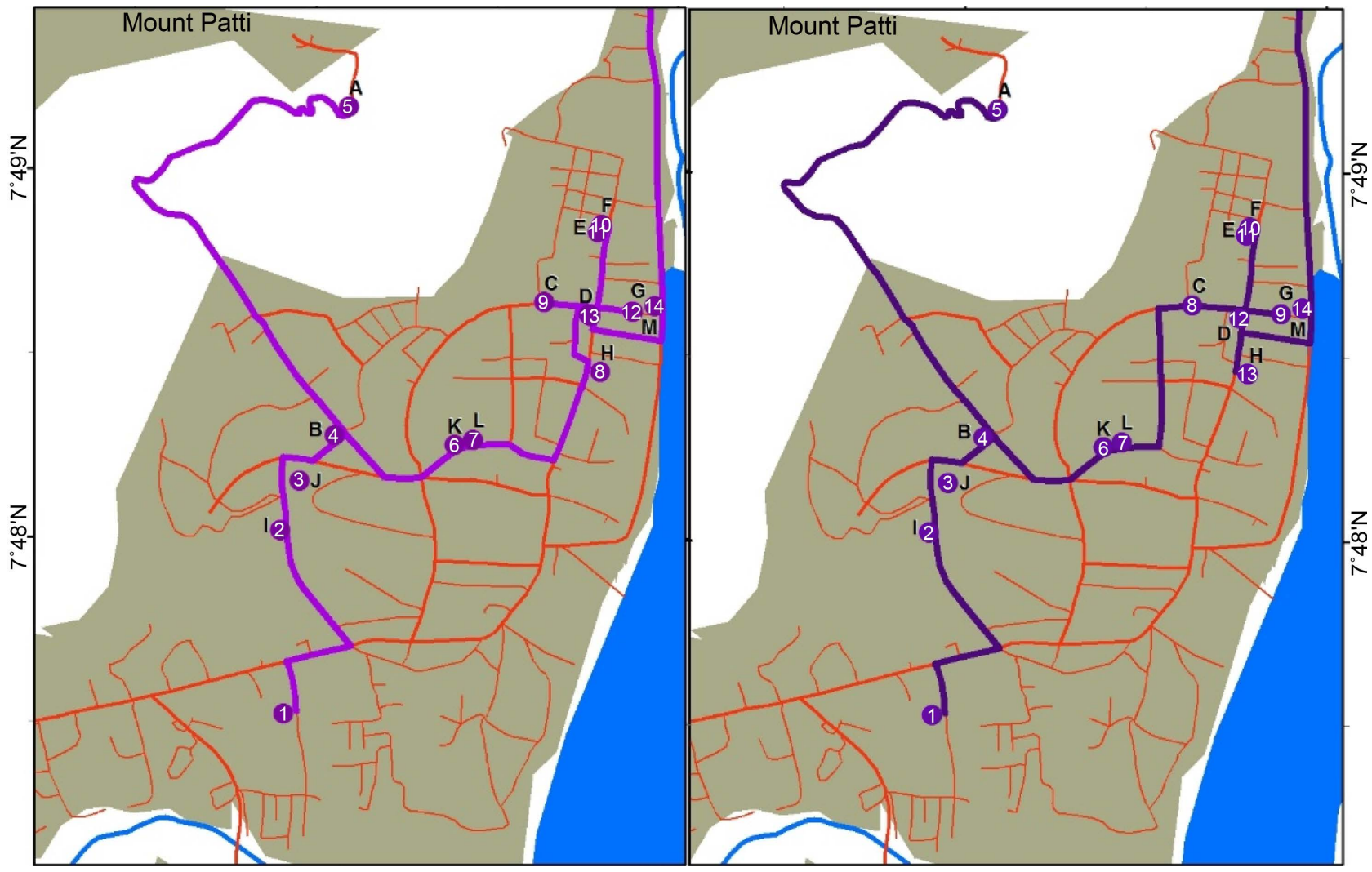

(b) 


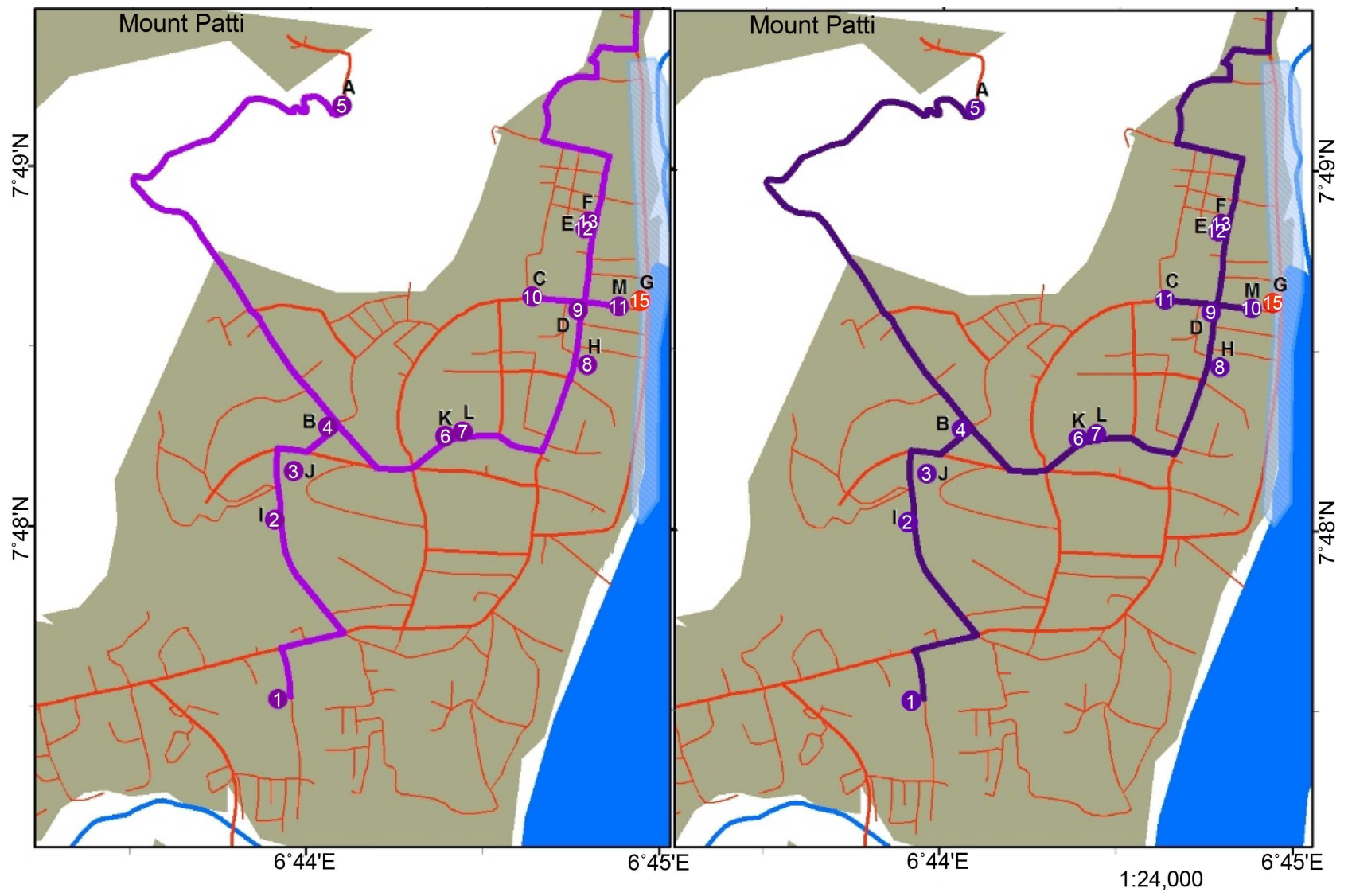

(c)

Figure 7. Maps of scenarios 3 (a), 4 (b) and 5 (c): The LHS maps are distance-optimized versions while the RHS maps are timeoptimized.

For the distance-optimized version, 20,929.92 meters was traversed over a 24.08 minutes duration; while for the time-optimized version, 21,136.62 meters was traversed during a 23.80 minutes period. In Figure $\mathbf{8 ( a )}$ is a graph that shows the distance-time relationship for this scenario in visiting the various sites on the tour while also comparing the distance- and time-optimized versions. Notice as with the previous cases that although the time-optimized version entailed the coverage of a longer distance, it took a shorter time than the distance-optimized version to complete the visitation of all the tourist sites. This is so because while time-optimized versions seek faster (but possibly longer) routes, the distance-optimized versions seek shorter (but possibly slower) routes. Hence, there is often the trade-off between distance covered and travelling duration between the two versions.

Scenario 4: This is a non-SOP as well as an open tour. Once the visitation sequence for this scenario was also optimized, there was a marked difference in the routes as well as the visitation sequence between the distance- and time-optimized versions, see Figure 7(b). From this figure, a comparison between the distance- and time-optimized version shows that the visitation sequence for all the other tourist sites remained the same except for sites C, D, H and M. Notice also the routes differences between the two versions. Essentially, 16,820.62 meters 

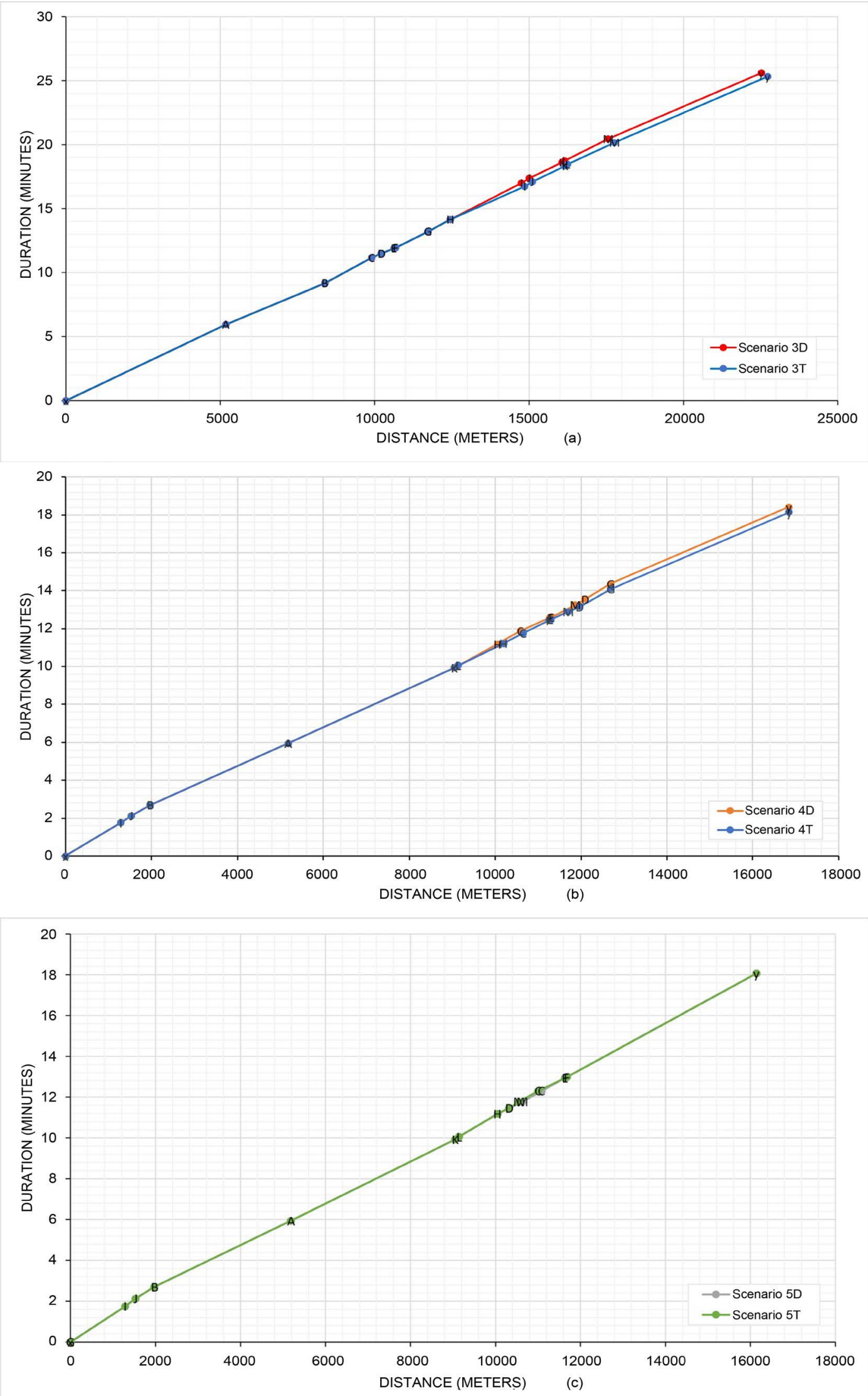

Figure 8. Graphs of scenarios 3 (a), 4 (b) and 5 (c). 
and 18.40 minutes were the distance and time respectively required for the distance-optimized version; while $16,841.09$ meters and 18.13 minutes were the distance and time respectively required for the time optimized version. In Figure 8(b) is a graph that shows the distance-time relationship for this scenario in visiting the various sites on the tour while also comparing the distance- and time-optimized versions in more details.

As with previous similar scenarios, while the distance-optimized version required a shorter cumulative distance than the time-optimized version; the timeoptimized version required a shorter travelling time than the distance-optimized version. However, for distance- and time-optimized non-SOPs, these differences in the associated cumulative travel distance and time were not so much as compared to SOPs. Furthermore, as previously observed, a comparison between scenarios 3 and 4 shows that scenarios wherein the site visitation sequence were optimized (i.e. non-SOPs) yielded better results (in terms of savings in both distance and time), than SOP scenarios; hence, the last scenario is a non-SOP.

Scenario 5: In this last scenario, a hypothetical flooding of the river Niger was considered, such that a good portion of the area along the bank of the river was off access. This area included a major connecting road segment for travels towards Abuja. See Figure 7(c) for further details. This is a non-SOP as well as an open tour. In this instance, the optimal routes required to visit all the tourist sites for the distance- and time-optimized versions were derived as shown in Figure 7(c). Notice that because of the flooding, site $G$ was cut off access because it was located in a flooded area whose access roads were also flooded. Furthermore, the same routes were traversed in visiting all the accessible tourist sites for both the distance- and time-optimized versions. The visitation sequence remained almost the same, except for an interchange in the visitation sequence for sites $\mathrm{C}$ and $\mathrm{M}$. For the distance-optimized version, site $\mathrm{C}$ was the $10^{\text {th }}$ and site $\mathrm{M}$ was the $11^{\text {th }}$ to be visited; while for the time-optimized version, site $\mathrm{C}$ was the $11^{\text {th }}$ and site $\mathrm{M}$ was the $10^{\text {th }}$ to be visited in the sequence. Cumulatively, about 16,138.1 meters and 18.07 minutes was required to visit all the tourist sites for both the distance- and time-optimized version. The difference between the two versions was too minute to be obvious in numbers with two decimal places. In Figure $8(c)$ is a graph that shows the distance-time relationship for this scenario in visiting the various sites on the tour while also comparing the distance- and time-optimized versions in more details.

These results also show that for SOPs, the differences in the cumulative travelling distance and duration for distance- and time-optimized versions would very minutely depending on the configuration of the transportation network as well as the spatial distribution of the tourist sites. Also, this scenario showed an instance wherein because of flooding, a potential tourist site was cut-off access for visitation. Several other factors could also cause the inaccessibility of certain sites; hence, optimal tour planning in a GIS environment could aid in determining which site could become inaccessible under certain circumstances (especially during disasters). 


\section{Summary of Findings from the Various Scenarios}

In addition to optimizing the travelling routes, distance and time; scenarios whereby the visitation sequence were optimized (i.e. non-SOPs) generally produced far better savings in distance and time than scenarios that were SOPs. Also, whenever there was a barrier (e.g. a road block or flooding) on a major connecting route for the sites visits; the required visitation distance and time became longer even if the visitation sequence was optimized. Furthermore, whenever the visitation sequence was optimized, the resulting solutions did not show much difference between the distance- and time-optimized versions.

\section{Strengths of the Transportation Network Model}

The average road speed varied by road type; hence there was a remarkable difference when an analysis was optimized for distance as against an analysis optimized for time. The transportation duration parameter was modelled with a Visual Basic script as against the more conventional rigid modelling using a rather static attribute field of the road network feature class. This makes it easier to vary the average transportation speed for different road types while considering different modelling scenarios. The modelling accounted for comprehensive routing directions through the network while visiting all the points of interest. In addition to producing realistic travel time results, the analysis was based on a rich set of geographic data and as such contained street names and street types as well as the names of the tourist sites.

\section{Options for Improving the Transport Network Model}

The current transportation network model for this article could be improved in the following ways: factor-in traffic congestions on different road segments as well as variations in congestions for different times of the day (i.e. peak \& off peak periods). Model turn restrictions/delays at road junctions including u-turns. For instance, in Nigeria, driving is on the right hand side of the road; therefore, right turns at junctions are usually faster than left turns. Also, based on the traffic specifications at certain junctions, left/right turns have been prohibited at selected road junctions. Consider one-ways as well as capacity constraints on various types of roads (i.e. certain types of vehicles are restricted on certain road because of their size or tonnage). Wide roads with multiple lanes would pose a special challenge, especially where there is a barricade (or non-cross lines) between the lanes. Modelling overpasses and underpasses (i.e. fly-overs) makes the network model more robust. Factor in take-off and arrival times for different days; visitation duration for each site as well as the opening or operation hours of the sites (as in the case with Kolyaise et al. [2]). Other cost factors that could be considered include amount of fuel consumption for cars or motorcycles, transport fare for motorcycles and taxis, calories burnt trekking or cycling etc. The network model could also account for other modes of transport, like walking, cycling, motor cycling, and lorries.

Furthermore, an optimal route planning analysis could be hosted as a geo- 
processing service on the internet thereby serving as a spatial decision support system (SDSS) for real time itinerary planning for the public. For a developing country (like Nigeria) with very low utilization of geographic information technologies, such SDSS will not only increase the public's awareness and interest in the technology, it will also help to justify and promote public spending in the diverse application areas of geographic information technology for societal benefit. Furthermore, it will foster the routine collection of high quality, detailed \& up-to-date geographic information especially about manmade features which are currently sparsely available. Such datasets once collected could readily be applied to several other uses beyond those for which they were originally created. For instance, an existing comprehensive geographic database of the currently security threatened north eastern regions of Nigeria would be invaluable to the Nigerian Armed Forces in carrying out their current operations there. The very high level of insecurity currently prevalent in those regions makes it very difficult to collect accurate geographic information about cultural (anthropogenic) features as these often requires extensive fieldworks. Also, the availability of such geographical datasets will invariably create the opportunity for other interesting applications.

\section{Benefits/Merits of GIS-Based Optimal Tour Planning}

Some of the benefits of a GIS-Based optimal tour planning include: Faster and optimal decision making leading to increased efficiency and productivity of individuals and organizations; Savings in man-hour (time) that would have been lost in taking more time-consuming routes. Conservation of resources like petroleum that would have been burnt in taking longer routes, in addition to the extra carbon dioxide that would have been emitted into the atmosphere thereby increasing the burdens of urban heat island (if in an urban area), global warming and other undesirable environmental effects. Reduction in the wares and tears on vehicles and roads that would have resulted from such extended journeys (i.e. vehicle usage reductions), as well as savings in the maintenance cost of the same. Savings in money spent in paying for public transport results directly from taking an optimal route and indirectly from many of the aforementioned advantages. There is also the savings in human energy (calories) that would have been wasted in decision making or in taking a less optimal route. Reduction in the wears and tears to transportation routes also increases the life span to the roads and helps save public funds that would have been used for road maintenance.

\section{Other Potential Applications of GIS-Based Optimal Tour Planning}

GIS-based network analyses can be applied to all forms of multi-site itinerary planning by both private individuals and public institutions. For instance, education supervisors interested in visiting (secondary or primary) schools, Doctors on call visiting multiple hospitals in the course of their routine activities. Itinerant academicians visiting multiple universities, security chiefs/supervisors (like 
the military, police, prisons etc.) visiting multiple out-post stations on routine inspections, production industries and their warehouses, raw materials and distribution chains etc.; During electioneering, supervisors may be interested in visiting several polling stations; agricultural extension workers may have to visit multiple farming location in short time; Evacuation planning during postdisaster response operations; collections of messages from post boxes by post office mail collectors; optimal routing between a conference venue and all the hotels (together with all the potential points of interest to the conference participants) could be analysed.

\section{Conclusions}

Because the study area is made up of different road types with varying transportation speeds, it was possible to get different results when optimizing for time and distance. Road congestions and some of the other cost variables mentioned in previous sections of this work could serve as other bases for optimization. Time-optimized versions of the various scenarios will be useful in emergency situations like health-related emergency transportation by ambulances as well as evacuation and rescue missions during disasters.

Though popular in developed countries (often hosted as services on the internet), existing route planning web sites application are not dynamic enough to capture the different scenarios in which tourists (or commuters) may be interested. Besides, those existing implementations leave rooms for improvements in the light of some of the suggestions proposed in this work.

\section{References}

[1] Kolyaie, S., Delavar, M.R. and Malek, M.R. (2008) A Framework of Spatial Decision Support System for Trip Planning Using Activity-Based Modeling. Proceedings of the Asian Conference on Remote Sensing, Colombo, 10-14 November 2008, 6.

[2] Kolyaie, S., Delavar, M.R. and Malek, M.R. (2009) Travel Itinerary Planning in Public Transportation Network Using Activity-Based Modeling. Journal of Applied Sciences, 9, 2532-2543. https://doi.org/10.3923/jas.2009.2532.2543

[3] Vaughna, K.M., Abdel-Aty, M.A. and Kitamura, R. (1999) A Framework for Developing a Daily Activity and Multimodel Travel Planner. International Transactions in Operational Research, 6, 107-121. https://doi.org/10.1111/j.1475-3995.1999.tb00146.x

[4] Bonsall, P.P., Firmin, M., Anderson, I., Paliner, P. and Balinforth, P. (1997) Validating the Results of a Route Choice Simulator. Transportation Research Part C: Emerging Technologies, 5, 371-387. https://doi.org/10.1016/S0968-090X(98)00003-5

[5] Tan, M.C., Tong, C.O. and Xu, J.M. (2004) Study and Implementation of a Decision Support System for Urban Mass Transit Service Planning. Information Technology and Management, 15, 14-32.

[6] Casas, I. (2003) Evaluating the Importance of Accessibility to Congestion Response Using a GIS-Based Travel Simulator. Journal of Geographical Systems, 5, 109-127. https://doi.org/10.1007/s101090300106

[7] Wijesinghe, K., Delpachithra, C.N., Perera, L., Wijetilake, S.H., Rajapaksha, S. and 
Fernando, N. (2013) GIS Enabled Travel Planner System with TSP Implementation. PNCTM, 2, 49-55.

http://dspace.sliit.lk/bitstream/123456789/184/1/49\%20-\%2055\%20GIS\%20ENABL ED\%20TRAVEL\%

[8] Jovanović, V. (2008) The Application of GIS and Its Components in Tourism. Yugoslav Journal of Operations Research, 18, 261-272. https://doi.org/10.2298/YJOR0802261J

[9] Chen, R.J.C. (2007) Geographic Information Systems (GIS) Applications in Retail Tourism and Teaching Curriculum. Journal of Retailing and Consumer Services, 14, 292. https://doi.org/10.1016/j.jretconser.2006.07.004

[10] Thill, J.C. (2000) Geographic Information Systems for Transportation in Perspective. Transportation Research, 8C, 3-12. https://doi.org/10.1016/S0968-090X(00)00029-2

[11] Duker, K. and Ton, T. (2001) GIS for Transportation. In: Hensher. D.A. and Button, K.J., Eds., Handbook of Transport Modeling, Elsevier, Oxford.

[12] Devarasetty, P.C. (2010) Finding a Reliable Route between Two Points in a Transportation Network Using GIS. Project Report, CVEN 658.

[13] Fan, W. and Machemehl, R.B. (2004) Optimal Transit Route Network Design Problem-Algorithms, Implementations and Numerical Results. Centre for Transportation Research.

[14] Bielli, M., Boulmakoul, A., et al. (2006) Object Modeling and Path Computation for Multimodal Travel Systems. European Journal of Operational Research, 175, 1705 1730. https://doi.org/10.1016/j.ejor.2005.02.036

[15] Huang, B. and Pan, X. (2006) GIS Coupled with Traffic Simulation and Optimization for Incident Response. Computers, Environment and Urban Systems, 31, 116-132. https://doi.org/10.1016/j.compenvurbsys.2006.06.001

[16] Huang, B., Yao, L. and Raguraman, K. (2006) Bi-Level GA and GIS for MultiObjective TSP Route Planning. Transportation Planning and Technology, 29, $105-$ 124. https://doi.org/10.1080/03081060600753404

[17] Jakimavicius, M. and Burinskiene, M. (2010) Route Planning Methodology of an Advanced Traveler Information System in Vilnius City. Transport, 25, 171-177. https://doi.org/10.3846/transport.2010.21

[18] Xia, X. (2009) Bus Trip Optimization at Directional Level in GIS. MSc Project, International Institute for Geo-Information Science and Earth Observation, Enschede.

[19] Dijkstra, E.W. (1959) A Note on Two Problems in Connection with Graphs. Numerische Mathematik, 1, 269-271. https://doi.org/10.1007/BF01386390

[20] Dantzlg, G.B. (1960) On the Shortest Route through a Network. Management Science, 6, 187-190. https://doi.org/10.1287/mnsc.6.2.187

[21] Black, P.E. (2012) Bellman-Ford Algorithm. Dictionary of Algorithms and Data Structures, US National Institute of Standards and Technology. http://www.nist.gov/dads/HTML/bellmanford.html

[22] Gohari, A., Ahmad, H.A., Hashim, M.G., Kheinmdiah, S. and Kumar, L. (2012) Towards the Design of GIS-Based Routing System. International Journal of Geoinformatics, 8, 63-69.

[23] Dial, R.B., Glover, F., Karney D. and Klingman, D. (1979) A Computational Analysis of Alternative Algorithms and Labeling Techniques for Finding Shortest Path Trees. Networks, 9, 215-248. https://doi.org/10.1002/net.3230090304

[24] Glover, F., Klingman, D. and Philips, N. (1985) A New Polynomially Bounded 
Shortest Paths Algorithm. Operations Research, 33, 65-73. https://doi.org/10.1287/opre.33.1.65

[25] Ahuja, R.K., Mehlhorn, K., Orlin, J.B. and Tarjan, R.E. (1990) Faster Algorithms for the Shortest Path Problem. Journal of the ACM, 37, 213-223. https://doi.org/10.1145/77600.77615

[26] Goldberg, A.V. and Radzik, T. (1993) A Heuristic Improvement of the Bellman-Ford Algorithm. Applied Mathematics Letters, 6, 3-6. https://doi.org/10.1016/0893-9659(93)90022-F

[27] Gallo, G. and Pallottino, S. (1988) Shortest Paths Algorithms. Annals of Operations Research, 13, 3-79. https://doi.org/10.1007/BF02288320

[28] Mondou, J.F., Crainic, T.G. and Nguyen, S. (1991) Shortest Path Algorithms: A Computational Study with the C Programming Language. Computers \& Operations Research, 18, 767-786. https://doi.org/10.1016/0305-0548(91)90014-I

[29] Cherkassky, B.V., Goldberg, A.V. and Radzik, T. (1993) Shortest Paths Algorithms: Theory and Experimenl Evaluation. Technical Report 93-1480, Computer Science Department, Stanford University, Stanford.

[30] De Smith, M.J., Goodchild, M.F. and Longley, P.A. (2009) Geospatial Analysis: A Comprehensive Guide to Spatial Analysis. Taylor, London.

[31] Ojaswa, S., Darka, M., Francois, A. and Girija, D. (2005) Traveling Salesperson Approximation Algorithm for Real Road Networks. Technical Report 388, Department of Geomatics Engineering, University of Calgary, Calgary.

[32] Bielli, M., Caramia, M., et al. (2002) Genetic Algorithms in Bus Network Optimization. Transportation Research Part C: Emerging Technologies, 10, 19-34. https://doi.org/10.1016/S0968-090X(00)00048-6

[33] Barra, A., Carvalho, L., et al. (2007) Solving the Transit Network Design Problem with Constraint Programming.

[34] Horn, M.E.T. (2002) Multi-Modal and Demand-Responsive Passenger Transport Systems: A Modelling Framework with Embedded Control Systems. Transportation Research Part A: Policy and Practice, 36, 167-188. https://doi.org/10.1016/s0965-8564(00)00043-4

[35] Lee, Y.J. and Vuchic, V.R. (2005) Transit Network Design with Variable Demand. Journal of Transportation Engineering, 131, 1-10. https://doi.org/10.1061/(ASCE)0733-947X(2005)131:1(1)

[36] Teodorovi, C. and Lučić, P. (2005) Schedule Synchronization in Public Transit Using the Fuzzy Ant System. Transportation Planning and Technology, 28, 47-76. https://doi.org/10.1080/0308106052000340387 
Submit or recommend next manuscript to SCIRP and we will provide best service for you:

Accepting pre-submission inquiries through Email, Facebook, LinkedIn, Twitter, etc. A wide selection of journals (inclusive of 9 subjects, more than 200 journals)

Providing 24-hour high-quality service

User-friendly online submission system

Fair and swift peer-review system

Efficient typesetting and proofreading procedure

Display of the result of downloads and visits, as well as the number of cited articles Maximum dissemination of your research work

Submit your manuscript at: http://papersubmission.scirp.org/

Or contact jgis@scirp.org 